\title{
Error Analysis Found in Students' Writing Composition in Simple Past Tense of Recount Text
}

\author{
Tira Nur Fitria \\ ITB AAS Indonesia \\ tiranurfitria@gmail.com
}

\begin{abstract}
This study was to find the types of error analysis and the most dominant form of error analysis found in the Simple Past Tense Writing Composition of Students, especially in Recount Text. This study used a mixed-method both qualitative and quantitative approach. From the study, it was shown that the error of the students in writing Simple Past Tense composition consists of certain elements of writing, such as grammar, punctuation, and spelling. There were 57 data in grammar, or $53.37 \%$, consisting of errors in class terms like in determiner/article ( 25 data or $43.86 \%$ ), in verb (14 data or $24.56 \%$ ), in a preposition (11 data or $19.30 \%$ ) and the last in a noun (7 data or $12.28 \%$ ). While the most dominant error was in determiner/article. Second, in the aspect of spelling, there were 26 data or $21.70 \%$ ). Third, in the aspect of punctuation, there were ( 23 data or $24.53 \%$ ). It is shown that the most dominant error found in the students' writing composition in the grammar aspect is 57 data or 53.37 percent based on the frequency of each aspect of error.
\end{abstract}

Keywords: Error, Error Analysis, Writing, Simple Past Tense, Recount Text

\section{INTRODUCTION}

In education, English has been taught from the kindergarten level up to the university level, but in fact, there are still many people who cannot comprehend English well. People must master four basic skills in English while studying English, namely listening, speaking, reading, and writing skills. These four skills are very important to master for those of you who study or want to master English.

The writing skill becomes the most complicated skill that should be mastered by the people, especially for the students because they

\section{ENGLISH FRANCA : Academic Journal of English Language and Education}

Vol. 4, No. 2, 2020, IAIN Curup

P-ISSN 2580-3670, E-ISSN 2580-3689

DOI: http://dx.doi.org/10.29240/ef.v4i2.1154, Page 141-160 
should be able to combine and express their feelings or opinion in a well-written form. In learning the English language, writing is one of the language skills that should be learned. Hasani (2005) notes that writing is a person's behavior in the rational and structured process of pouring concepts, emotions, and feelings into written form so that the reader can understand the letter. Therefore, indirectly, the primary role of writing is as a medium of communication. Writing means a process of communication that conveys ideas and opinions in a written form which suggests that the writers and the readers should have a similar understanding of what is written.

The writing method is an interrelated series of recursive stages, according to Harmer (2007) which include drafting, structuring, concentrating, generating ideas, and evaluating. Brown (2007) notes that writing is often the product of thought, drafting, and revising processes requiring specialized skills, an ability that is acquired naturally by not every speaker. In short, writing is a product bypassing the process of thinking the ideas (planning), drafting, revising, evaluation (editing) until the final draft. Therefore, writing often is a complex process in learning English (Heydari \& Bagheri, 2012).

There are guidelines for writing English, which can make it a challenging language to learn. In particular, some of the fields where language learners struggle with grammar, punctuation, and spelling. A significant part of writing is grammar. Besides, punctuation and spelling are also important in writing because English writing has language components. These can not be isolated from each other since another aspect is connected to them. Students may improve their thought skills and their English skills, such as grammar and vocabulary, through writing activities (Jayanti, 2019). In helping students to write sentences and then texts that make sense and flow well, spelling, vocabulary, grammar, and punctuation are key elements.

For some students, writing in English is not easy. When they use the language of writing, they will have problems. When they write, they do not know the correct one, then they make errors (Karim et al., 2018). There will be errors because of this, which can be seen in their prose. 
Students have several difficulties writing English, so the writing of goods produces an error. An error here includes three categories, they are morphological errors, semantic errors, and syntactic errors (Liu, 2008). While students use the target language than making errors during second language learning can be seen as a means of developing the skills of students so they can learn more by making errors. Errors may be triggered by a lack of language abilities, such as the lack of understanding of the proper target language rules by the learner (Fitria, 2020). While, James (2013) states that error analysis is the way to determine the nature of the event, causes, and impacts of inadequate language.

According to Richards \& Schmidt (2002), in linguistics, an error is the use of a phrase, a speech act, or grammatical elements in such a way that incomplete learning appears imperfect and significant. Although error analysis is a tool used to record errors that occur in the language of the learner, it determines if those errors are systemic and describe what causes them (if possible). The errors can occur by using tense in writing paragraphs or composition because tenses are necessary for English texts. Students are often confused about how to use tense when writing a sentence. An unavoidable aspect of language learning is errors typically committed by the second foreign language learner. The learners can improve their skills by making errors and hearing the right forms from the instructor.

Errors are the marks of learners who have not learned the rules of English (Fitria, 2019). For both learners and instructors, errors and their review are also beneficial. The teacher's challenge is to find ways to trigger the passive awareness that the students have in terms of writing skills in a meaningful way, as well as helping students become more competent when trying to eradicate some of their common errors. (Fitria, 2018), because an error is one of the teacher's concerns (Ferris, 2011, p. 129). The errors of English learners should also be carefully examined as these errors represent the learning process of a language. (Wu \& Garza, 2014). 
The simple past tense is used for events or circumstances that started and ended in the past, according to Cowan (2008), the students usually write recount text in the simple past tense, and have to know simple past tense well. Because, awareness of simple past tense, which in writing the experience, is required in writing recount text. The text of the recount is a piece of text that records past occurrences, usually in the order in which they took place (Anderson \& Anderson, 1997).

Previous research related to the analysis of errors is available. Fitria (2015) has written research about Error Analysis in Writing Simple Future Tense. This study found the type of error shown in the writing composition of students in the elements of grammar, punctuation, and spelling. This study used the qualitative study to obtain analytical evidence from the written knowledge of the students. The data will be correctly obtained by the use of this tool. The outcome of the study indicates that the error of the students in writing simple future tense composition consists of three aspects of writing such as grammar, punctuation, and spelling.

Based on the above description, the researcher is interested in performing the same study on error analysis, but distinct research data entitled 'An Error Analysis Found in Students' Writing Composition of Simple Past Tense in Recount Text". In terms of grammar, punctuation, and spelling, this study points out the types of error analysis found in the Students' Writing Composition and points out the most dominant form of error analysis found in Simple Past Tense in Students ' Writing Composition.

\section{RESEARCH METHODOLOGY}

This research uses a mixed-method in both qualitative and quantitative research. Qualitative research is one of social research that adopts both versatile and data-driven research style, uses relatively unstructured data, emphasizes the subjectivity's role in the research, and uses verbal analysis as a statistical type (Hammersley, 2013, p. 12).

In qualitative, the writer used descriptive design because the data obtained related to the information that focuses on current status and phenomena. In conducting this study, the writer considers that the 
descriptive method is suitable. While this study focused more on the qualitative descriptive approach, it also uses a quantitative approach. It was important to use numerical data to obtain accurate and countable data. Therefore, in this analysis, the quantitative approach was conducted to see the percentage and frequencies to support the research data. As stated by Treiman $(2014$, p. 1$)$ that the most basic quantitative analyses are inf the form of cross-tabulations or percentage tables.

The study object is the writing composition of 19 students taken from 15 Diploma (D3) students of STIE AAS Surakarta. As a result of the student's composition in writing simple past tense, especially in recount text, the students ' writing composition here.

The researcher uses document in gathering the details. All of the documents are linked to the reporting process. It can be in the form of a newspaper, a textbook, a letter, a piece of paper, an email, a test result, etc. A document can be said as any symbolic representation that is recorded and retrieved for description and analysis (Hesse-Biber \& Leavy, 2010, p. 127). The researcher analyzes the writing of the students in the recount text as the data in this report. Besides, the researcher studied the paper to uncover the error made by the students in writing a simple past tense of recount text.

Ellis (1997) claimed that error detection, error classification, error definition, error interpretation, and then tabulation were the steps to evaluate the errors. Finally, the data was tabulated to recognize the frequency of errors made by the students.

In the identification of errors. The writer described the errors of the students in writing the recount text in this stage, including the use of a proper noun, descriptive phrases, simple past tense, and time connective. In error definition, the errors were categorized into some categories in this stage. Besides, the definition of the error was to describe the variations in word disorder between the utterances of students and the reconstruction of target language utterances. In explanation of errors. The writer clarified the cause of an error made by the students in this phase. By anticipating it, the writer tried to find out the cause of the error. In the tabulation of errors, the writer drew the error into a table to tabulate based on the classification of errors. The 
number of errors created by the students and then found out the most dominant errors in student writing.

\section{FINDINGS AND DISCUSSION}

\section{Findings}

The findings of this analysis are intended to solve the research objectives as formulated in the study context. This study found the sort of error analysis found in students' writing and the most dominant kind of error analysis found in students' writing. Below, the explanation of the student writing errors as follow:

\section{Grammar}

Harmer (2007) describes grammar as an explanation of how words in that language can alter their forms and can be combined into phrases. Brown (2007) describes that grammar is the set of rules that control a sentence's traditional arrangement and connection of words. Without grammar, we cannot make a good language and the language we produce will not be understood by others. Therefore, grammar is an important part of the language that can make the language clearly or unclearly understood. Grammar errors usually happen because the writer does not understand how to use punctuation marks. Below the errors which are found in students' writing composition, as follow:

\section{Determiner/Article}

Example 1

Wrong : This is my activity when holiday yesterday.

Correct : This is my activity when a holiday/the holiday yesterday.

The example shows an error in the determiner/article. It appears in that sentence that an article is missing before the phrase "holiday." It is needed to be changed when an article "a" or "the" is inserted. Therefore, it should be written "a holiday" or "the holiday".

Example 2

Wrong : We also took the time buy souvenir. 
Correct : We also took the time buy a souvenir/the souvenir.

The example shows an error in the determiner/article. It appears in that sentence that an article is missing. It is needed to be changed when an article "a" or "the" is inserted. Therefore, it should be written "a souvenir" or "the souvenir".

Example 3

Wrong : It was a best holiday.

Correct : It was the best holiday.

The example shows an error in the determiner/article. In that sentence, the expression "a best" does not seem to include the correct use of the article. It is needed to be added the article "the." Therefore, it should be written "the best."

Example 4

Wrong : Therefore, we wanted to go to city.

Correct : Therefore, we wanted to go to a city/the city.

The example shows an error in the determiner / article. It appears in that sentence that an article is missing before the phrase "holiday." It is needed to be changed when an article "a" or "the" is inserted. Therefore, it should be written "a city" or "the city".

Example 5

Wrong : Last holiday in new year, my family and I went to...

Correct : Last holiday in a new year/the new year, my family and I went to...

The example shows an error in the determiner/article. In that sentence, the expression "a best" does not seem to include the correct use of the article. The article "a" or "the" is needed. Therefore, it should be written "a new year" or "a new year." 


\section{Verb}

Example 1

Wrong : ... what should I do to filled my holiday

Correct : ... what should I do to fill my holiday

The example shows an error in the verb. The base form is required by the to-infinitive that follows the verb "filled." The shift of the term "packed" to the base form or verb 1 "fill".

Example 2

Wrong : ...until I didn't realized, time for pray Dzuhur was arrived.

Correct : ...until I didn't realize, time for pray Dzuhur was arrived.

The example shows an error in the verb. In the above sentence, the verb "realized" seems to be wrongly used with the supporting verb "did" in the past. It is modified to the base type. Therefore, it should be written, "realize".

Example 3

Wrong : ...time for pray Dzuhur was arrived...

Correct : ...time for pray Dzuhur arrived/has arrived...

The example shows an error in the verb. It uses the transitive verb "arrived" in a passive voice construction in the sentence above. The phrase in the active sentence is needed in the text. Therefore, it should be written " arrived "or" arrived.

\section{Example 4}

Wrong : ...so many people came to Parangtritis to spent their time. Correct : ...so many people came to Parangtritis to spend their time.

The example shows an error in the verb. In the above sentence, it appears that as part of the to-infinitive following the word "came" the verb "spent" should be in the base form. It is needed to change its term into "spend" verb 1. 


\section{Example 5}

Wrong : ... we went to the tourist spot which become a favourite place Correct : ... we went to the tourist spot which becomes a favourite place

The example shows an error in the verb. The plural verb "become" does not appear to agree with the singular topic "the tourist spot" in the sentence above. It is needed to be changed when modifying the form of the verb for the subject-verb agreement. Therefore, it should be written, "becomes".

\section{Example 6}

Wrong : ...we played in the beach; we decided to went home soon.

Correct : ...we played in the beach; we decided to go home soon.

The example shows an error in the verb. In the above sentence, it appears that as part of the to-infinitive following "decided" the verb "went" should be written in the base form. It is needed to be changed when modifying the form of the verb. Then, it should be written, "go".

\section{Preposition}

Example 1

Wrong : ...for young people specially for their problem about love.

Correct : ...for young people specially for their problem with love.

The example shows an error in the preposition. "In this sense, it appears that the preposition" about "might be incorrect. In modifying an acceptable preposition "with".

\section{Example 2}

Wrong : At 2 pm I went to home but before I went to home, Correct : At 2 pm I went to home but before I went to home,

The example shows an error in the preposition. "It seems needless to write the preposition" to "after the verb" went "in that sentence. It is considered to delete the acceptable preposition" to. 
Example 3

Wrong : We went on the 2nd trip in cave Gong.

Correct : We went to the 2nd trip in cave Gong.

The example shows an error in the preposition. It appears in that sentence that the preposition 'in' in this sense may be incorrect. In modifying an acceptable preposition "to".

\section{Example 4}

Wrong : Around at 14.00, we arrived in our second destination.

Correct : Around at 14.00, we arrived at our second destination.

The example shows an error in the preposition. It appears in that sentence that the preposition 'in' in this sense may be incorrect. It is needed to be changed in modifying the necessary preposition "at."

\section{Example 5}

Wrong : At 14th January 2018 we did that plan.

Correct : On 14th January 2018 we did that plan.

The example shows an error in the preposition. It appears from that sentence that the preposition 'at' in this sense may be incorrect. A suitable preposition "on" is considered when adjusting.

\section{Noun}

Example 1

Wrong : ..., we saw many beautiful view such as rice fields, mountains.

Correct : ..., we saw many beautiful views such as rice fields, mountains.

The example shows an error in the noun. The quantifier "many" follows the singular countable noun "view", which includes a plural noun. Using a plural noun or a separate quantifier is considered. "This should therefore be converted into the required" views "plural noun.

Example 2

Wrong : It turns out the voice is my brother voice. 
Correct : It turns out the voice is my brother's voice.

In the above case, it shows an error in the noun. It appears in the sentence above that the noun "brother" should be in the possessive sense. It is considered when changing the form of a noun. Therefore, it should be written "brothers".

Example 3

Wrong : After three hour rode my car,...

Correct : After three hours rode my car,...

The example shows an error in the noun. A number other than one follows the singular noun 'hour'. It must change the shift of the noun to the plural noun "hours".

\section{Example 4}

Wrong : ...but we have little problems ,...

Correct : ...but we have little problem ,...

The example shows an error in the noun. The definitive article ' $a$ ' with the plural noun 'problems' may not be needed in the above sentence. The shift of the noun to the singular is considered. Therefore, it should be written 'problem.'

\section{Example 5}

Wrong : ...there are still many guest who arrive.

Correct : ...there are still many guests who arrive.

The example shows an error in the noun. The singular countable noun "guest" follows the quantifier "many" in the above sentence, which includes a plural noun. This is considered by using a plural noun. Therefore, it should be written "guests".

\section{Spelling}


The spelling of such arrangements of letters is related to spelling. One of the basic components of effective writing is spelling, the art of correctly assembling words from their letters. Spelling errors typically happen when the writer does not understand how to correctly spell the words. Some errors found in the composition of the students ' writing are as follows:

Example 1

Wrong : ..., so we went to a Chinese restaurant.

Correct : ..., so we went to a Chinese restaurant.

The example shows an error in the spelling. The word "Chinese" is not in the dictionary or miswritten in that sense. It is needed to be changed when modifying an acceptable term. Therefore, it should be written "Chinese".

Example 2

Wrong : because so colourfully decorated by fireworks.

Correct : because so colorfully decorated by fireworks.

The example shows an error in the spelling. The spelling of "colourfully" in that sense is a non-American version. For continuity, it is substituted by the American spelling of English. It should, therefore, be "colorful."

Example 3

Wrong : I wanted to have a lot of time hangout with my family at home. Correct : I wanted to have a lot of time hang out with my family at home.

The example shows an error in the spelling. It is possible to use the term 'hangout' incorrectly. Determining the best use for this context is considered. A space between the words 'hang' and 'out' should be applied to the term 'hangout'.

Example 4

Wrong : ...for young people specially for their problem about love. 
Correct : ...for young people especially for their problem with love.

The example shows an error in the spelling. The word "specially" may be used incorrectly in that sense. Suitable use for this context is assumed to be decided. "It should be written "especially".

\section{Example 5}

Wrong : ...because can not see the sun rise.

Correct : ...because cannot see the sunrise.

The example shows an error in the spelling. The word "can not" seems to be miswritten in the sentence above. It is taken into account by removing a space while replacing it or translating it into suitable writing. It ought, therefore, to be "can not." Whereas it seems that the term "sun rise" is miswritten. It is taken into account by removing a space while replacing it or translating it into suitable writing. It should be written "sunrise."

Example 6

Wrong : ...we went to the tourist spot which become a favourite place... Correct : ...we went to the tourist spot which become a favorite place...

The example shows an error in the spelling. In that context, a nonAmerican variant is the spelling of "favourite." For continuity, it is substituted by the American spelling of English. Therefore, it should be written "favorite."

\section{Punctuation}

Punctuation is a symbol used in sentences to build meaning, clarity, and tension. To organize and organize our writing, we use punctuation marks. Punctuation illustrates how to interpret the word and make the context clear, so writing becomes difficult to read without punctuation. Punctuation is very important as it enables a piece of text to make sense to the readers. Typically, punctuation errors arise because the writer 
does not understand how to use punctuation marks. Among the errors found in the writing composition of students are as follows:

Example 1

Wrong : Finally we decided to go home at $06.00 \mathrm{pm}$ on that day. Correct : Finally, we decided to go home at $06.00 \mathrm{pm}$ on that day.

The example shows a punctuation error. In that sentence, a comma after the initial word "Finally" seems to be absent. It is called a comma to be applied. "It should be written "Finally, ....".

\section{Example 2}

Wrong : After that we went to GembiraLoka zoo.

Correct : After that, we went to GembiraLoka zoo.

The example shows a punctuation error. In that sentence, a comma after the initial word "That" seems to be absent. It is called a comma to be applied. It is expected to be written, "After that, ....".

\section{Example 3}

Wrong : On the beach we can not just swim the beach or play water and sand.

Correct : On the beach, we can not just swim the beach or play water and sand.

The example shows a punctuation error. In that sentence, a comma after the introductory phrase "On the beach" appears to be absent. It is called a comma to be applied. "Therefore, it should be written "on the beach,...

Example 4

Wrong : In his house we chatted jokingly.

Correct : In his house, we chatted jokingly. 
The example shows a punctuation error. In that sentence, a comma after the introductory phrase "In his house" appears to be absent. It is called a comma to be applied. It should be written, "In his house, ..."

Example 5

Wrong: On the night day the weather was very bad.

Correct : On the night day, the weather was very bad.

The example shows a punctuation error. In that sentence, after the introductory phrase "On the night day" a comma appears to be missing. It is needed a comma after "On the night day, ...".

Example 6

Wrong : We would go to Bandungan together, because we need holiday.

Correct : We would go to Bandungan together because we need holiday.

The example shows a punctuation error. In this case, it appears that after the dependent clause marker "because". There is an unnecessary comma after the term "because".

\section{Discussion}

The systematic study of language errors is Error Analysis (EA). This study of the errors found can be learned from and weeded out systematically. Error analysis is also a valuable method for understanding the learner's progress in a foreign language. Error analysis gives a fascinating insight into the comprehension of the language learning process. It helps teachers by providing feedback on the errors made by the learners/students to understand the new ways of teaching. It is certain and acknowledged that in the course of learning, learners make errors. These errors provide language teachers and linguists with new ideas and methods to address problems related to language learning. 
In the aspect of grammar, punctuation, and spelling, this research points out the type of error analysis found in the Students' Writing Composition and points out the most dominant type of error analysis found in Simple Past Tense Writing Composition of Students. Errors in the grammar, punctuation, and spelling aspects are found below the table of the outcome of the writing composition of the students.

Table 1.

Frequency of Error in Students' Writing Composition

\begin{tabular}{|c|c|c|c|c|c|c|}
\hline \multirow[t]{3}{*}{ ASPECT } & \multicolumn{4}{|c|}{ Grammar } & \multirow[b]{2}{*}{ Spelling } & \multirow[b]{2}{*}{ Punctuation } \\
\hline & $\begin{array}{c}\text { Determiner/ } \\
\text { Article }\end{array}$ & Verb & Preposition & Noun & & \\
\hline & $\begin{array}{c}25 \\
43.86 \%\end{array}$ & $\begin{array}{c}14 \\
24.56 \\
\%\end{array}$ & $\begin{array}{c}11 \\
19.30 \%\end{array}$ & $\begin{array}{c}7 \\
12.28 \\
\%\end{array}$ & 26 & 23 \\
\hline TOTAL & \multicolumn{4}{|c|}{57} & & \\
\hline$\%$ & \multicolumn{4}{|c|}{$53.37 \%$} & $21.70 \%$ & $24.53 \%$ \\
\hline
\end{tabular}

The table indicates from the table above that three aspects of language, such as grammar, punctuation, and spelling, consist of the students' errors in language simple past tense composition. First, there are 57 data or 53.37 percent in the aspect of grammar, consisting of errors in some points of the class word such as determiner/article (25 data or 43.86 percent), verb (14 data or 24.56 percent), preposition (11 data or 19.30 percent) and last noun (7 data or 12.28 percent) in certain points of the class word. While the determiner/article was found to be the most dominant error. Second, there are 26 data, or $21.70 \%$, in the spelling aspect). Third, there is (23 details or 24.53 percent) in the aspect of punctuation. It shows that the most prevalent error found in the writing composition of the students is in the grammar aspect as 57 data or 53.37 percent based on the frequency of each aspect of error writing. There are three aspects of writing below the student's study and explanation of the error in writing composition of simple past tense, as follows:

In the grammar aspect, first. The grammar aspect is the first rank of the type of error analysis found in the writing composition of Simple Past Tense by students. There are some errors in the class words (part 
of speech) in this study, such as determiner/article, verb, preposition, and noun. In verb, in writing, the learners have several errors. There are some errors in the determiner/article, such as 1) missing article before some sentences. 2) A certain word in the world follows the writing of incorrect article usage. "Both errors are taken into account when adding an article" a "or" the. There are some errors in the verb, such as 1) Toinfinitive writing. Some words don't obey the law that the base form includes a certain verb. 2) Writing verbs that help. Some words are written wrongly. In changing those words into the basic form of verb 1 , all errors are taken into account. 3) Transitive verb writing. In a passive construction, there is a word that is written. Therefore, the sentence in the active sentence is assumed to be written, and 4) Writing an incorrect subject-verb agreement. A term is incorrectly written there. With the singular subject, the plural verb does not seem to agree. It is also taken into consideration when altering the verb. There are some errors in a preposition, as it appears in some examples that the preposition may be incorrect in such contexts. Therefore, the modification of an appropriate preposition is considered. There are some errors in nouns, such as 1) writing improper singular and plural nouns. The singular countable noun follows the "many" quantifier, which requires a plural noun, and the plural noun does not need the definitive article "a". 2) Writing the noun's possessive form. A phrase in the example appears that the noun should be in the possessive form. It is taken into account when changing the form of a noun.

In the spelling factor, second. The spelling aspect is the second rank of the type of error analysis found in the writing composition of Simple Past Tense by students. There are some errors in this study, such as 1) writing incorrect sentences. Some words in the illustration shown are not found in the dictionary or are miswritten. Therefore, in this sense, a suitable term or use is assumed to be modified. 2) Non-American variants of writing. A non-American variant is the spelling of certain words. For continuity, it is considered to be substituted by the American spelling of English.

Third, in the context of punctuation. The punctuation factor is the third rank of the type of error analysis found in the writing composition 
of Simple Past Tense by students. Missing a comma following the introductory sentences. The phrases in the examples indicate that after the introductory phrase "Finally", "After that" etc., a comma is absent. Hence, adding a comma after it is considered. 2) Missing a comma after the marker with the dependent clause. The phrases in the examples indicate that there is an excessive comma after the 'since' dependent clause marker. After the term "because" it is considered when removing the comma.

However, many of the errors found in student assignments are generally straightforward. Students may be blamed or even lose marks because certain rules of English have been ignored by them. Good writing requires good grammar, spelling (orthography), and punctuation. Technically, spelling and punctuation may not be included in grammar, but we need all these elements in our prose. As these are distinct but related components that work together to create a technically sound piece of writing, we speak about grammar, spelling, and punctuation. The elements of good writing are simple: grammar, punctuation, and spelling. We will make our writing easy to understand and more enjoyable for our readers by mastering the rules and conventions.

\section{CONCLUSION}

From the review of this study, it reveals that the errors of the students in Simple Past Tense writing composition consist of grammar, punctuation, and spelling. First, there are 57 data or 53.37 percent in the aspect of grammar, consisting of errors in some points of the class word such as determiner/article ( 25 data or 43.86 percent), verb (14 data or 24.56 percent), preposition ( 11 data or 19.30 percent) and last noun (7 data or 12.28 percent) in certain points of the class word. While the determiner/article was found to be the most dominant error. Second, there are 26 data, or $21.70 \%$, in the spelling aspect). Third, there is (23 data or 24.53 percent) in the aspect of punctuation. It shows that the most prevalent error found in the writing composition of the students is in the grammar aspect as 57 data or 53.37 percent based on the frequency of each aspect of error writing. The important elements for good writing: grammar, pronunciation, and punctuation. We will make 
our writing easier to understand and more fun for our readers by mastering the rules and conventions.

\section{REFERENCES}

Anderson, M., \& Anderson, K. (1997). Text Types in English. Macmillan Education Australia.

Brown, H. D. (2007). Principles of Language Learning and Teaching. Pearson Longman.

Cowan, R. (2008). The Teacher's Grammar of English with Answers: A Course Book and Reference Guide. Cambridge University Press.

Ellis, R. (1997). Second Language Acquisition. OUP Oxford.

Ferris, D. (2011). Treatment of Error in Second Language Student Writing, Second Edition. University of Michigan Press.

Fitria, T. N. (2018). Error Analysis Found in Students' Writing Composition of Simple Future Tense. 12.

Fitria, T. N. (2019). Errors in Students' Writing Composition in Simple Present Tense "My Daily Activity." Edulangue, 2(1), 47-62. https://doi.org/10.20414/edulangue.v2i1.318

Fitria, T. N. (2020). Error Analysis of English Abstract in International Journal of Economics, Business and Accounting Research (IJEBAR). Al-Lisan, 5(2), 164-181. https://doi.org/10.30603/al.v6i2.1335

Hammersley, M. (2013). What is Qualitative Research? A\&C Black. Harmer, J. (2007). The Practice of English Language Teaching. Pearson Education.

Hasani, A. (2005). Ihwal Menulis. Untirta Press.

Hesse-Biber, S. N., \& Leavy, P. (2010). Handbook of Emergent Methods. Guilford Press.

Heydari, P., \& Bagheri, M. S. (2012). Error Analysis: Sources of L2 Learners' Errors. Theory and Practice in Language Studies, 2(8), 1583-1589. https://doi.org/10.4304/tpls.2.8.1583-1589

James, C. (2013). Errors in Language Learning and Use: Exploring Error Analysis. Routledge. 
Jayanti, A. D. (2019). Student's Writing Ability on English Descriptive Text at Grade VIII in SMPN 33 Padang. ENGLISH FRANCA: Academic Journal of English Language and Education, 3(01), 71. https://doi.org/10.29240/ef.v3i01.843

Karim, A., Mohamed, A. R., Ismail, S. A. M. M., Shahed, F. H., Rahman, M. M., \& Haque, Md. H. (2018). Error Analysis in EFL Writing Classroom. International Journal of English Linguistics, 8(4), 122. https://doi.org/10.5539/ijel.v8n4p122

Liu, Y. (2008). The Effects of Error Feedback in Second Language Writing. Journal of Second Language Acquisition and Teaching, 15, 15.

Richards, J. C., \& Schmidt, R. W. (2002). Longman Dictionary of Language Teaching and Applied Linguistics. Longman.

Treiman, D. J. (2014). Quantitative Data Analysis: Doing Social Research to Test Ideas. John Wiley \& Sons.

Wu, H., \& Garza, E. V. (2014). Types and Attributes of English Writing Errors in the EFL Context-A Study of Error Analysis. Journal of Language Teaching and Research, 5(6), 1256-1262. https://doi.org/10.4304/jltr.5.6.1256-1262 